\title{
Overweight and Obesity in Youth with Type 1 Diabetes: What is Known?
}

ISSN: 2578-0263

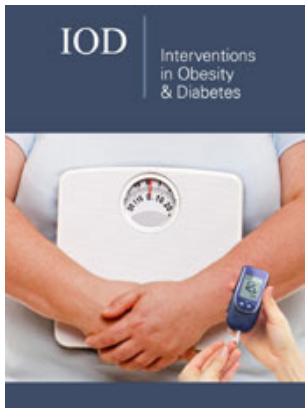

*Corresponding author: Bruce King, Department of Paediatric Endocrinology and Diabetes, John Hunter Children's Hospital, Newcastle, Australia

Submission: 眥 June 20, 2020

Published: 醋July 07, 2020

Volume 4 - Issue 3

How to cite this article: Alexandra Marlow, Carmel Smart, Rowen Seckold, Bruce King. Overweight and Obesity in Youth with Type 1 Diabetes: What is Known? Interventions Obes Diabetes 4(3) IOD.000588. 2020.

DOI: 10.31031/IOD.2020.04.000588

Copyright@ Bruce King. This article is distributed under the terms of the Creative Commons Attribution 4.0 International License, which permits unrestricted use and redistribution provided that the original author and source are credited.

\author{
Alexandra Marlow, Carmel Smart, Rowen Seckold and Bruce King* \\ Department of Paediatric Endocrinology and Diabetes, John Hunter Children's Hospital, Australia
}

\begin{abstract}
Obesity is a modifiable risk factor for poor health outcomes including cardiovascular disease (CVD). A trend for elevated body weight in children with type 1 diabetes (T1D) compared to the general population is clearly evident. This trend is pronounced in teenage girls with T1D and increases with age. Teenage boys with T1D more closely resemble the population norms for overweight and obesity. Given that individuals with T1D are at an increased risk of early CVD related morbidity and mortality, early weight management intervention could potentially improve CVD outcomes. Further investigation of mechanisms of weight gain in T1D is required to inform interventions.
\end{abstract}

Keywords: Type 1 diabetes; Pediatric; Obesity; Weight gain

Abbreviations: T1D: Type 1 Diabetes; CVD: Cardiovascular Disease; DCCT: Diabetes Control and Complications Trial; Diabetes Prospective Study; BMI-SDS: Body Mass Index Standard Deviation Score; MVPA: Moderate-to-Vigorous Physical Activity

\section{Introduction}

Overweight and obesity is an established risk factor for serious health outcomes including cardiovascular disease (CVD) [1] and increased mortality [2]. Individuals with type 1 diabetes (T1D) face an unequivocal risk of CVD similar to that seen in people with type 2 diabetes [3]. Atherosclerotic changes have been shown to affect individuals with T1D at younger ages, beginning in childhood. In the German/Austrian DPV registry, an alarming 69\% of the 27,000 youth with T1D had one or more CVD risk factor [4]. The landmark Diabetes Control and Complications Trial (DCCT) established that in people with T1D, glycemic control was a determinant of microvascular disease highlighting the need for intensive insulin therapy to minimize long-term diabetes-related complications [5]. However, the DCCT also demonstrated significant weight gain in the intensive therapy arm compared to the conventional treatment arm [6].

\section{Rate of Overweight and Obesity in Youth with T1D}

Recent research has demonstrated an increased rate of overweight and obesity in children with T1D. The Australasian Diabetes Data Network found that 33\% of children and adolescents with T1D were overweight or obese [7] compared to 25\% of the pediatric population in the Australian National Health Survey [8]. Youth with T1D from the Diabetes Prospective Study (DPV) in Europe and the Type 1 Diabetes Exchange (T1DX) in America had a higher median body mass index standard deviation score (BMI-SDS) is compared to respective national reference samples [9]. The SEARCH for diabetes in youth study found significantly higher rates of overweight but not obesity in young people with T1D (3-19 years) compared to the general US population [10]. Stratification by age and gender revealed that females aged 12-19 years with T1D had significantly higher rates of combined overweight or obesity compared to the population reference ( $36.5 \%$ and $29.1 \%$, respectively). Interestingly, the opposite was true in boys aged 12-19 years with T1D, where the rates in the population reference were significantly higher (28.8\% and $34.6 \%$, respectively) [10]. 
Research at our center demonstrated an overweight and obesity rate of $37 \%$ in children and adolescents with T1D compared to $24 \%$ for an age matched population [11]. Whilst combined overweight and obesity were significantly higher in males and females in the 5-8 year age group compared to the general population, this effect disappeared in the 9-12 year age group across sexes. Thereafter, only girls had significantly higher rates of combined overweight or obesity in the adolescent (13-16 years) and young adult groups (18-24 and 25-30 years) compared to the general population. In addition, BMI-SDS was associated with a longer duration of diabetes in girls only [11].

\section{What are the Mechanisms of Weight Gain in Youth with} Type 1 Diabetes?

Contributing factors influencing childhood obesity in youth without diabetes include insufficient physical activity, dietary factors, sleep duration [12] and socioeconomic factors [13]. An analysis of the DPV cohort showed BMI-SDS increase during the course of T1D was strongly associated with female gender in youth. Moreover, the study found specific diabetes-related factors which contributed to weight gain over time, including higher insulin dose, low BMI-SDS at diabetes onset, longer diabetes duration, intensive insulin therapy and pubertal diabetes onset (aged 10-15 years) also contributed to weight gain over time [14]. There are few studies have objectively measured moderate-to-vigorous physical activity (MVPA) levels in youth with T1D compared to healthy subjects found significantly lower rates of MVPA in youth with T1D diabetes [15]. Children with T1D may face additional barriers to those experienced by children in the general population. Fear of hypoglycemia, low fitness level and loss of control of diabetes have been identified as significant barriers to physical activity in youth over 12 years of age. Furthermore, 91\% of youth also indicated that their parents discouraged physical activity [16]. Research has demonstrated that disordered eating behaviors are more common in adolescent girls with T1D compared to their peers [17]. Interestingly, disordered eating behaviors were correlated with elevated BMI-SDS in youth with T1D in the SEARCH study [18].

\section{Management of Overweight and Obesity in Youth with T1D}

Management of obesity in youth with T1D is usually done on a case-by-case basis. In the general population lifestyle interventions focusing on diet, physical activity and behavioural interventions have shown some benefit [19]. However, behavioural interventions in the general population focus on physical activity and nutrition in children but are not tailored to the unique set of circumstances encountered by children and adolescents with T1D. Factors such as glucose fluctuations caused by exercise and dietary considerations in the setting of T1D present a key challenge to work on in future interventions.

\section{Conclusion}

Both T1D and overweight and obesity carry increased and independent risk for CVD. Hence, weight management in youth with T1D is important. Recent research has highlighted that weight management should start early in adolescence and be directed towards females with T1D. However, mechanisms of weight gain and methods to address diabetes-related barriers to physical activity and weight loss are currently lacking and require further research.

\section{References}

1. Klein S, Burke LE, Bray GA, Blair S, Allison DB, et al. (2004) Clinical implications of obesity with specific focus on cardiovascular disease: A statement for professionals from the American Heart Association council on nutrition, physical activity, and metabolism: endorsed by the American College of Cardiology Foundation. Circulation 110(18): 2952-2967.

2. Adams KF, Schatzkin A, Harris TB, Kipnis V, Mouw T, et al. (2006) Overweight, obesity, and mortality in a large prospective cohort of persons 50 to 71 years old. The New England Journal of Medicine 355(8): 763778.

3. Pang TT, Narendran P (2008) Addressing insulin resistance in type 1 diabetes. Diabet Med 25(9): 1015-1024.

4. Schwab KO, Doerfer J, Hecker W, Grulich Henn J, Wiemann D, et al. (2006) Spectrum and prevalence of atherogenic risk factors in 27,358 children, adolescents, and young adults with type 1 diabetes. Cross-sectional data from the German diabetes documentation and quality management system (DPV). Diabetes Care 29(2): 218-225.

5. Nathan DM, Genuth S, Lachin J, Cleary P, Crofford O, et al. (1993) The effect of intensive treatment of diabetes on the development and progression of long-term complications in insulin-dependent diabetes mellitus. The New England Journal of Medicine 329(14): 977-986.

6. (1995) Adverse events and their association with treatment regimens in the diabetes control and complications trial. Diabetes care 18(11): 1415-1427.

7. Phelan H, Clapin H, Bruns L, Cameron FJ, Cotterill AM, et al. (2017) The Australasian diabetes data network: first national audit of children and adolescents with type 1 diabetes. The Medical Journal of Australia 206(3): 121-125.

8. (2017-2018) Australian Bureau of Statistics. National Health Survey, Australia.

9. DuBose SN, Hermann JM, Tamborlane WV, Beck RW, Dost A, et al. (2015) Obesity in youth with type 1 diabetes in Germany, Austria, and the United States. The Journal of Pediatrics 167(3): 627-632.

10. Liu LL, Lawrence JM, Davis C, Liese AD, Pettitt DJ, et al. (2010) Prevalence of overweight and obesity in youth with diabetes in USA: The SEARCH for diabetes in youth study. Pediatric Diabetes 11(1): 4-11.

11. Marlow AL, Rowe CW, Anderson D, Wynne K, King BR, et al. (2019) Young children, adolescent girls and women with type 1 diabetes are more overweight and obese than reference populations, and this is associated with increased cardiovascular risk factors. Diabetic Medicine 36(11): 1487-1493.

12. Poorolajal J, Sahraei F, Mohamdadi Y, Doosti Irani A, Moradi L (2020) Behavioral factors influencing childhood obesity: A systematic review and meta-analysis. Obesity Research \& Clinical Practice 14(2): 109-118.

13. Shrewsbury V, Wardle J (2008) Socioeconomic status and adiposity in childhood: A systematic review of cross-sectional studies 1990-2005. Obesity (Silver Spring) 16(2): 275-284. 
14. Fröhlich Reiterer EE, Rosenbauer J, Bechtold Dalla Pozza S, Hofer SE, Schober E, et al. (2014) Predictors of increasing BMI during the course of diabetes in children and adolescents with type 1 diabetes: data from the German/Austrian DPV multicentre survey. Archives of Disease in Childhood 99(8): 738-743.

15. Trigona B, Aggoun Y, Maggio A, Martin XE, Marchand LM, et al. (2010) Preclinical noninvasive markers of atherosclerosis in children and adolescents with type 1 diabetes are influenced by physical activity. The Journal of Pediatrics 157(4): 533-539.

16. Jabbour G, Henderson M, Mathieu ME (2016) Barriers to active lifestyles in children with type 1 diabetes. Canadian Journal of Diabetes 40(2): 170-172.
17. Young V, Eiser C, Johnson B, Brierley S, Epton T, et al. (2013) Eating problems in adolescents with type 1 diabetes: A systematic review with meta-analysis. Diabet Med 30(2): 189-198.

18. Nip ASY, Reboussin BA, Dabelea D, Bellatorre A, Mayer Davis EJ, et al. (2019) Disordered eating behaviors in youth and young adults with type 1 or type 2 diabetes receiving insulin therapy: The SEARCH for diabetes in youth study. Diabetes Care 42(5): 859-866.

19. Oude Luttikhuis H, Baur L, Jansen H, Shrewsbury VA, O Malley C, et al. (2019) Interventions for treating obesity in children. Cochrane Database of Systematic Reviews. 